\title{
College Transformation through Enabling Agility
}

\author{
Mary S. McCully and Elizabeth A. McDaniel \\ Information Resources Management College, \\ Washington, DC
}

\author{
mccullym@ndu.edu mcdaniele@ndu.edu
}

\begin{abstract}
Government organizations and universities are traditional and bureaucratic institutions. One government-sponsored graduate-level college undertook a transformation to develop agility in spite of academic traditions and a risk-averse culture to take advantage of Information Age concepts, opportunities, and tools. As a result, the college, dedicated to developing information leaders who can leverage information and information technology for strategic advantage, is becoming increasingly agile. By engaging stakeholders, the college is sensing the learning needs of government organizations, and re-designing current, and developing new programs and tailored educational services. Through its large distributed learning program, the college is reaching students around the world, and is expanding its global reach by supporting communities of practice. College leaders streamlined the organizational design to create teams of faculty to develop and deliver programs responsive to student needs. Replacing command-and-control systems, the leaders are re-framing the organization's reason for being, governing principles, and high-level business process design.
\end{abstract}

Keywords: Agility, sense-and-respond, transformation, netcentricity, information age

\section{Introduction}

Government organizations and universities are among the most traditional and bureaucratic institutions. Yet, in the Information Age agility is a key competency for survival and success. Recognizing the need to be more responsive and agile in an increasingly turbulent environment, a government-sponsored graduate-level college undertook a transformation to develop its agility in spite of academic traditions and risk-averse cultures. Starting in the mid-1990s, the college began taking advantage of Information Age concepts, opportunities, and tools and embraced the concept of agility. While maintaining and enhancing its academic rigor as a college in a regionally accredited graduate institution the college began transforming from a traditional hierarchical Industrial Age college with a resident population enrolled in a limited number of offerings to an Information Age net-centric agile college.

Being agile allows the college to sense and respond to today's dynamic unpredictable environ-

Material published as part of this publication, either on-line or in print, is copyrighted by the Informing Science Institute. Permission to make digital or paper copy of part or all of these works for personal or classroom use is granted without fee provided that the copies are not made or distributed for profit or commercial advantage AND that copies 1) bear this notice in full and 2) give the full citation on the first page. It is permissible to abstract these works so long as credit is given. To copy in all other cases or to republish or to post on a server or to redistribute to lists requires specific permission and payment of a fee. Contact Publisher@InformingScience.org to request redistribution permission. ment. Its agility relies on its ability to develop netcentric relationships and to pulse current student, stakeholder, and organizational needs and business environments worldwide, and anticipate the future. An agile culture fosters innovation and initiative, self-organization and governance drive its operations and policies. The college is actively engaging its network of respected partners. Its business processes meet the dynamic 
information demands and expectations of its students, faculty, and staff. It resources appropriate hardware, software, courseware and data bases enable information gathering and sharing, and supports an engaged academic community. This case study attempts to link organizational theory from the literature of the corporate world, defense and government reform, and higher education to one college's experience. The paper describes the essential elements of an agile organization and how one college strategically became more agility to achieve its mission. The final section of the paper identifies the metrics of the college's success in becoming an agile government and academic organization that might contribute to its value as a model for other organizations.

\section{Organizational Survival in Turbulent Times}

In today's turbulent environment, the behavior of customers and competitors is no longer predictable. Decision cycles are compressed because of nearly synchronous communication and accelerating expectations for engagement. Planning cycles are being overtaken by demands for greater responsiveness that can only be achieved through increased organizational ability to gather relevant information from the environment and to respond effectively and quickly. Rapid prototyping and speed to market are essential. Ubiquitous information and communication technologies are radically changing personal, professional, and organizational lives. Resulting freedoms from the constraints of real time and space are leading to the globalization of the economy, culture, and values.

Successful organizations need strategies to leverage information and information technology for strategic advantage to survive and be sustainable in, and help influence, the unpredictable world. They need to develop new networks for global connectivity, and capabilities for real-time collaboration, rapid and continuous information-sharing that facilitate shared situational awareness, boundaryless interaction and leadership opportunities, and ubiquitous access. Through communication and collaboration large, complex organizations can adapt systematically for flexibility, agility, and responsiveness. They must go beyond the traditional model of "make-and-sell" to develop their information-gathering, decision-making capabilities, and internal operations to "sense-and-response" to meet evolving customer needs (Haeckel, 1999).

Agility is a key component of transformation. While all organizations need to continue to operate to some degree as "make-and-sell" organizations, they need to grow their capacities to be agile, to sense and respond and shape the environment if they are to compete in the $21^{\text {st }}$ Century marketplace. By gathering and leveraging information, agile organizations are able to customize products and services to meet the changing needs of their current and new customers by seeking, receiving, processing, and using real-time information to make decisions.

Just like private sector organizations, traditional institutions like government and higher education need to become more agile to survive in turbulent times. "Rapidly evolving information technology (IT) has played an important role in expanding our capacity to generate, distribute, and apply knowledge, which in turn has produced unpredictable and frequently disruptive change in existing social institutions" (Duderstadt, Wulf, \& Zemsky, 2005, p. 35). While some colleges and universities are taking advantage of information and communication technologies for many of their functions, the culture and core functions of teaching and learning at most institutions are still very traditional. The new entrepreneurial universities and a few innovative and responsive units of traditional universities are becoming net-centric and agile, but both higher education and government are still primarily "make and sell" institutions, and by their very nature adapt very slowly to environmental changes.

The federal government is being challenged to transform its bureaucratic systems and organizations for the $21^{\text {st }}$ Century (Walker, 2006). The specialized and rule-based processes of the Industrial Age federal bureaucracy grew in response to the size, complexity, and demands of government of an earlier time. Today, however, the inefficiency, opacity, cost, and unresponsive nature 
of government are out of line with Information Age opportunities and expectations, demands for efficiency, and dissatisfaction of citizens, suppliers, and employees. According to David Walker, Comptroller General of the United States, transformation is essential to head off the impending crises in the budget deficit, Social Security, and Medicare. While some innovative efforts for egovernment are underway, the fundamental culture, nature, and core processes of government have changed little in the past decade. The U.S. Department of Defense, despite its traditional hierarchical structure based on command-and-control systems and culture, is committed to transforming to netcentricity to facilitate agile and sense-and-respond behavior and cultures possible (Grimes, 2004).

\section{Enabling Agility with Netcentric Information}

Net-centricity, as defined for business in the $21^{\text {st }}$ Century or the future military force, has five capabilities: global connectivity; real-time collaboration; rapid and continuous information sharing that leads to shared situational awareness, boundaryless interaction and leadership opportunities; and ubiquitous access (Lentz 2002; Peat 2003; Zavin 2004). "Net-centricity creates an information-rich environment populated by vastly increased number of valuable information sources that can be effectively discovered and utilized by those who need and can benefit from it" (Fritzon 2005 , p. 2). Netcentricity is a "transformation enabler that empowers all users with the ability to easily discover, access, integrate, correlate and fuse data/information that supports their mission objectives" (Zavin 2004, p. 4). The desired outcomes of net-centric communication are agile decisions that are timely, informed, more robust and dispersed, and authority and responsibility dispersed across a flatter organization (Lentz 2002; Myers 2004). Initiative, adaptability, and innovation are encouraged because members of the net-centric network are engaged, informed, and empowered (Peat 2003) to respond to and shape the environment.

Effective real-time information allows an organization to develop its capacity to sense and respond. According to Haeckel (1999), in sense-and-respond organizations adaptiveness takes precedence over efficiency because change is continuous. In contrast with make-and-sell organizations in which change was predictable, efficiency was the priority, and planning could take place on long-term cycles, sense-and-respond organizations are designed to gather and act upon their dynamic and unpredictable environment. If growth depends on finding and developing new ways to establish sustainable competitive advantage, operational effectiveness, productivity, and efficiency are necessary, but are not enough. According to research conducted by Gartner, today's companies must innovate and create new market segments, distribution channels, product categories, service offerings, and production processes (Austin, 2006). "Agility is the ability of an organization to sense environmental change and respond efficiently and effectively to that change" (Plummer \& McCoy, 2006, p. 1). Four fundamental capacities enable organizations to increase their agile performance: awareness, flexibility, adaptability, and productivity. Awareness is proactive sensing and data gathering. Flexibility is the ability to respond appropriately to expected changes, while adaptability is the ability of the organization to respond to unexpected changes by adding options. Productivity is the capacity to respond effectively and efficiently with substantial internal changes that require innovation, involve risk, and are potentially disruptive (Plummer \& McCoy, 2006). Being agile requires depth of human capital to respond to environmental conditions and priorities. If all organizational resources are tied up delivering current products or services, the organization cannot respond with agility when conditions require effort in a new way or area.

In order to sense and respond effectively and efficiently the leadership of agile organizations must be more distributed than in command-and-control hierarchical organizations. Decision making must be more decentralized in a culture in which the purpose and scope of the business are clear to everyone (Haeckel, 1999, p. 93). Governing adaptive organizations requires a context for behavior, not a means for dictating it. The context consists of three elements: a reason for being 
that articulates the organization's essential purpose, governing principles that set boundaries on allowable behavior, and a high level business design for how critical elements interact to fulfill the reason for being (p. 103-4). Transforming to a sense-and-respond organization requires leadership commitment to create a new culture, capacities, systems, rewards, and behavior. Distributed leadership supported by rich networked communication and coordination are proving effective.

\section{Developing Agility to Achieve the Mission}

Since the mission of the college is to develop leaders who can leverage information for strategic advantage, among the metrics of its success are the number of qualified students who successfully complete courses and customized workshops conducted by faculty, recognition by stakeholders and partners, global reach, faculty collaboration and productivity as scholars, and financial stability.

During its mid-1990s environmental scan, the college assessed and anticipated the changing needs of its students and stakeholders. Its prospective students (mid- to senior-level government leaders) would soon realize their need for continuous life-long learning, flexible, reliable, and robust information, and on-demand communication systems driven by the global nature and information intensity of their jobs. The operational tempos of their organizations would likely continue to increase, keeping these professionals chained to their offices or in the field, and out of traditional classrooms. Budgets were almost guaranteed to be tightened with support for traditional in-resident learning at risk. In response, the leadership deliberately set a course toward agility and net-centricity by embracing six enterprise practices: sense and respond to the current environment while anticipating the future, transform and model leadership of an agile culture, build and leverage collaborative networks, create processes that enable agility, resource technologies that enable agility, and shape the environment.

\section{Sense and Respond to Current Environment}

Only by scanning the environment and anticipating its direction, characteristics, and potential opportunities can a net-centric organization remain relevant and agile (Alberts \& Hayes, 2003). In higher education the landscape is continually changing in accordance with the needs and expectations of the students, stakeholders, and faculty and the creation of new knowledge and technologies. The college's federal agency and defense civilian and active duty military students are life-long learners who work in stressed organizations where the operational tempos and declining budgets continue to limit their attendance in traditional residential courses. With downsizing, government organizations must achieve their missions with fewer government employees and more contractors. For the remaining government employees education becomes even more critical.

In response to expressed learner needs, the college offers courses in various formats. The longest program requires fourteen weeks in residence, but the same certificate program can be completed by taking eight individual courses in any order over four years offered in residence and in distributed learning (online) formats. Most students still enroll in courses taught in residence on campus, but approximately 20 percent of course enrollments are in interactive seminar distributed learning offerings with no residence required.

The college expanded its array of courses and programs into specialized areas (e.g., enterprise architecture and information technology project management) in response to needs expressed by students, alumni, and stakeholder organizations, validated by faculty assessment of workforce/professional trends and needs. Stakeholders often endorse the need for workforce learning associated with individual courses but many are not interested in credit for certificates or graduate degrees; therefore, the college now actively markets the professional development option as well 
as certificate and graduate credit. The college is also engaging in "education in context" activities on topics of varying depth, for various audiences and purposes. This responsiveness to expressed stakeholder needs and interests has led to exciting engagements for faculty members and increased the college's global reputation. Being responsive requires developing organizational capacity that allows for the real-time realignment of personnel and adjustments to workload, metrics and rewards for faculty, as well as agile resources to develop curriculum and new customized products.

\section{Transform and Model Leadership of an Agile Culture}

The college is transforming into a net-centric agile organization from one that was more traditionally governmental and military in its culture, hierarchy, internal focus, department-centric, residential location, and paper-based curriculum and business processes. To become an agile organization the college leadership must model and support collaboration, rapid and continuous information access and exchange, and global connectivity. The college leadership is evolving the culture by encouraging, rewarding, and modeling collaboration across diverse functions and departments both internally and externally. By sharing information and delegating responsibility for decision-making downward to department chairs and faculty members means that the leadership is distributing accountability and responsibility for quality. The leadership regularly and deliberately communicates its expectations for curriculum and instruction to become agile, such that every course must be enriched by e-learning so that enrolled students, even in resident offerings, can access e-learning lessons in the distributed learning formats in case a natural or manmade emergency prevents delivery of instruction on campus.

To set the context, leaders must articulate a clear sense of mission and purpose, the governing principles that set boundaries for distributed leadership and responsibility, and a high level business design (Haeckel, 1999). The college leaders set strategic goals that require net-centric operations to provide learning opportunities for students, business processes of the college, and professional and organizational partnering, cross-boundary collaborating, and global connectivity in physical and virtual space. To increase its partnerships the college expanded its engagement with organizations, private and public, domestic and global, for concept development, academic programs, and timely learning. The leadership expects faculty to foster valuable network partnerships in their academic and professional fields. The college's pioneering efforts in tele-work policy recognized by a national award in 2004 required the integration of new technologies, business process, and policies for communication, productivity, and trust. Faculty are equipped with the appropriate hardware, software, and communication resources to facilitate learning, advise students, conduct research, and participate in college operations 24/7 remotely, even internationally, as necessary. The college facilitates agility in teaching via its very successful interactive distributed learning (DL) model by weighting DL teaching as time and a half credit in calculating faculty teaching loads.

\section{Build and Leverage Collaborative Networks}

Effective networks are composed of partners who participate for mutual benefit (Peat, 2003; Zain, 2004). The networks of the college are composed of stakeholders, academic and professional colleagues and public and private sector organizations. Fluid self-organizing student- and facultyaccessible ubiquitous communities of interest are forming to share information, knowledge, and businesses processes across these networks. Agile organizations require networks be extensive and robust, and connectedness with networks be ongoing, meaningful, and sensing.

The college recognizes the value of building and leveraging networks. It seeks to be a partner of choice in its niche, information leadership and information resources management. It commits to engage stakeholders in the private sector, international, defense and federal government organiza- 
tions, and other strategic decision makers and communities of interest in knowledge-sharing and creation. Students while enrolled in courses over a two- to four-year period are encouraged to be active members of the learning communities developed in and out of class to advance their professional and organizational needs, and to continue as active alumni. Connected and involved alumni provide essential feedback on current and future issues in their organizations, offer students perspectives that enrich theory and research, and contribute as valuable members of the college-supported communities of practice that underpin the college's network. Effective networks engage partners from international, domestic federal, state, and local governments as well as the academic and private sectors with common interests who appreciate the power of, the need for, and benefits of sharing. Network-centric organizations recognize that knowledge shared is stronger and more valuable than knowledge that is held, especially information with a short shelf life, and particularly in situations with increased operational tempo. Through its expanding network of partners, the college enlarges its knowledge base, satisfies student demand for network growth (McCully \& Schulin, 2004), connects to key stakeholders and experts in multi-leveled networks, and looks for opportunities to collaborate as a respected global network partner.

In 2005, the college embarked on a multi-faceted outreach initiative. Key messages led to branding the college and its programs, and the development of new outreach products such as brochures, posters, a website, a stakeholder-focused briefing, and a conference booth. These products are designed to communicate with stakeholders about the college and its courses, programs, and services to meet their workforce needs and to offer strategic partnership opportunities. The college keeps track of interfaces, constituencies, and stakeholders with whom faculty and leaders have contact, and the follow up that is necessary and desirable. As a result, the network of partners is expanding exponentially, enabling the college to collect more real-time information it is using to adapt its courses, programs, and services to meet stakeholder needs.

Leveraging its key message, "a learning community for government's most promising information leaders", the college launched a web-based system to support communities of practice in the information resources management field. Faculty members support several communities on a system purchased and managed by the college. The college's community of learners, formal and informal, local and global, and U.S. and international, is growing.

\section{Create Processes that Enable Agility}

Net-centric organizations create processes that enable global connectivity, real-time collaboration, rapid and continuous information exchange that is boundaryless and ubiquitous, and access to data and information that is secure and reliable. In a net-centric agile higher education organization, these capabilities require processes very different from those used in the traditional hierarchical academic, government, or military organization. They rely on processes at the learning and business levels that connect beyond the campus to deliver equal or better e-services to faculty, students, and partners.

In the mid-1990s, the college began exploring tools and technologies to create media-rich instructional materials and experimenting with e-learning environments to support the interactive seminar model, first for students in residence and then online. By fostering innovation and developing consensus about the learning principles and models, technology, and tools, the college began creating its highly effective virtual learning environment. In this environment student are active builders of knowledge and faculty are innovators in the teaching and learning process. Another core process, the collaborative development of interdisciplinary curriculum, engages faculty from across the college and relies on net-centric $24 / 7$ access from campus, home, or any global location to each other and to curriculum materials and courseware on shared network drives. Curriculum documents are electronically available and archived, as are instantiations of each distributed learning offering. 
Government support of employees to travel to campus for resident course offerings is often limited by competing job requirements and organizational funding. But students continue to need and want access to high quality professional development, graduate learning, and opportunities to network with others engaged with the same professional challenges. In response the college offers every course in resident format on campus as well as in asynchronous distributed learning (DL) format to meet student needs for learning and networking anytime and any place. Both modes create highly interactive learning environments that are of equal high quality (McCully \& Schulin, 2004). Currently over 20 percent of the college's total offerings are in the DL mode to offer access to students who live locally, across the country, and around the globe.

Most of the college's other core processes have become net-centric, enabling all members, on and off campus, to meet their needs effectively when conducting the business of education. Student (and faculty) access to all the library resources is another process that is transformed. All enrolled students have 24/7 password-controlled web access to library resources. The college's processes for application and registration for courses and programs are now web-based for global student access and action. Faculty, staff, and students are able to access course content, schedules, and password-controlled student records that reflect real-time reliable data information. The faculty and staff can order course materials; schedule classes and rooms; arrange, approve, and request reimbursements for travel using the web-based 24/7 systems.

\section{Resource Technology that Enables Agility}

Netcentric capabilities allow the college to sense and respond to student, stakeholder, and practitioner interests and needs, share information, and facilitate learning. Information and communication technologies that are secure, reliable, affordable, expandable, interoperable, and userfriendly by faculty, staff, and students on site and in remote locations enable a networked college community for global connectivity, real-time collaboration, continuous information-sharing, boundaryless interaction and leadership, and ubiquitous access.

The software that supports the college business processes is web-based, user hardwareindependent, and accessible remotely. Courseware, all of which satisfies federal legislative mandates to meet the access needs of students and faculty with disabilities, is supported on the Blackboard course management system. It allows faculty to conduct interactive courses that are globally accessible via dial up or digital high speed link connections by students across town, country or globe, or in the campus classroom. Access to all data and course information is passwordcontrolled to protect the student privacy, comply within the copyright laws, and respect the intellectual property of faculty. Instructional designers partner with faculty to enrich learning materials and develop media objects.

Mobile communication devices support global connectivity of the faculty and leadership to promote shared situational awareness, informed decision-making, and self-synchronization. Relational data bases facilitate one-stop-shopping for most business activities. A new curriculum management system is being implemented to facilitate the management of a collaborative curriculum development process, and knowledge management to support version control and archiving of documents, media, and curriculum. Commercially developed software supports the communities of practice initiative that is expanding the college's traditional role in education with more continuous, informal, just-in-time, facilitated communities of practice. As described, expanded net-centric capabilities are enabling agility in decision making and action.

\section{Anticipate the Future and Shape the Environment}

The expression "sense-and-respond" resonates with the faculty of the college as we reflect on the college's transformation over the past few years. But the term does not fully describe the essential elements or the impact of the college's transformation. Faculty members often add two verbs 
that relate to the future to the term sense-and-respond that they view as too reactive. They add "anticipate and shape" to explain the significance of activities the College is undertaking and to capture the active and powerful nature of our new culture and attitude. The outreach and education-in-context activities do not just pulse demand, they are creating it by educating potential students and stakeholders about information leadership. The college actively shares best practices with wide networks of colleagues and associates in the public and private sector, and civilian universities. The college is also seeding innovation in its graduates who are information leaders who are transforming government and shaping the environments in which they operate. The preferred term is now "sense and respond, anticipate the future, and shape the environment."

\section{Conclusion}

In the mid-1990s when a graduate-level college inside the federal government scanned the environment and anticipated the frontier beyond the horizon, it deliberately and enthusiastically undertook six enterprise strategies: sense and respond to the current environment while anticipating the future, transform and model leadership of an agile culture, build and leverage collaborative networks, create processes that enable agility, resource technologies that enable agility, and shape the environment. The college embraced evolving net-centric concepts as enablers of agility to sense and respond to the changing needs and expectations of its future students who wanted, needed, and more importantly, expected global boundaryless and ubiquitous access, and an information rich environment. The college sensed the power of the network paradigm, now referred to as net-centricity, and commenced to exploit it, thereby creating a new model for an agile government and academic organization. The college changed its systems for sensing and responding to the environment, leadership policies and derived culture, role in an expanded partnership community, internal processes and educational models and products, and priorities and capabilities of its technologies. The college's students, life-long learners employed around the world in demanding mid- to senior-level positions, information and technologically savvy and already very cognizant of the power of networks, demanded net-centric educational models and eservices. The leadership set the course to become increasingly agile, and continues to resource the commitment. The college now has a global student body engaged in life-long professional learning and networking. Its students, faculty, and staff access the learning environment to meet their learning needs $24 / 7$ from any location, when they are ready to learn or do business. The faculty are active participants in global networks in their areas of expertise, who develop and deliver leading edge curricula in near real-time. Global and domestic partners from the private and public sectors seek opportunities to collaborate with the college on a variety of critical issues, initiatives, and levels.

To survive in its turbulent environment, the college became agile. The college systematically transformed in response to anticipated student and stakeholder needs, and shaped its environment by creating demand in new areas through its leadership and expertise. By all measures the college is achieving its mission to develop leaders who can leverage information for strategic advantage. The number and quality of students has been maintained, albeit in a wider range courses, workshops, and programs delivered in a variety of formats that respond to the expressed needs of stakeholders. Faculty members are in demand as experts, are actively collaborating with colleagues across government and the private sector, and are engaged in scholarly activities. The global reach of the college has expanded with increased enrollment of international students and capacity-building projects with a half-dozen countries. Financial resources of the college are enriched by maintaining tuition revenues of students and revenues from customized services and programs for stakeholder organizations.

As the environment for higher education becomes more dynamic and uncertain, colleges and universities (and government organizations) need to be more agile to achieve their missions. They may wish to consider these six enterprise strategies grounded in the literature for success in envi- 
ronments characterized by constricted resources, new competitors, new modes and tools for teaching and learning, and new types of learners. The future remains unpredictable, truly challenging, and very exciting for those institutions that can become agile in responding to and shaping the needs of their students and stakeholders.

\section{Disclaimer}

The views expressed in this article are those of the authors and do not reflect the official policy or position of the National Defense University, the Department of Defense, or the U.S. Government.

\section{References}

Alberts, D., \& Hayes, R. (2003). Power to the edge: Command and control in the information age. Washington, D.C.: CCRP Publication.

Austin, T. (2006, March 30). Achieving agility: Growth, agility, and high-performance workplace strategies are intimately linked (Gartner No G00138286). Gartner, Inc.

Duderstadt, J. J., Wulf, W.A., \& Zemsky, R. (2005, Fall). Envisioning a transformed university. Issues in Science and Technology, 22(8), 35-42.

Fritzon, A. (2005). Net-centricity survival guide: utilizing communities of interest (COIs) to exploit information overload. Workshop presented at the Network Centric Warfare Conference, Washington, D.C. Retrieved December 14, 2006, from http://www.idga.org/iowarobot/document.html? event $=5517 \&$ topic $=222 \&$ document $=47334 \& \#$

Grimes, J. (2004). The power of information: Access, share, collaborate. Washington, D.C.: Office of the DoD Chief Information Officer. Retrieved December 14, 2006, from http://www.dod.mil/cionii/docs/info_access_flip_book.pdf

Haeckel, S. H. (1999). Adaptive enterprise: Creating and leading sense-and-respond organizations. Boston: Harvard Business School Press.

Lentz, R. (2002, March). Information assurance and DoD: A partnership with industry. Retrieved December 14, 2006, from http://www.itaa.org/infosec/assurance.pdf

McCully, M.., \& Schulin, K. (2004). Click and bricks: Transforming education. Academic Exchange, 8(2), 91-95.

Myers, M. (2004, Oct). Netcentricity transforming the way DoD shares information (A DOD NII/CIO briefing). Retrieved December 14, 2006, from http://www.input.com/external/events/conference/fedfocus 2005/presentations/keynote morning_mmyers.pdf

Plummer, D.C., \& McCoy, D.W. (2006, April 21). Achieving agility: The view through a conceptual framework (Garter No G00137820). Gartner, Inc.

Peat, B. (2003). Becoming Netcentric. Retrieved December 14, 2006, from http://businesscentricmethodology.com/CMS/documents/BCM.BecomingNetCentric.2003-06-18a.pdf

Walker, R.W. (2005, July 13). $21^{\text {st }}$ century challenges: Transforming government to meet current and emerging challenges. Testimony before the Subcommittee on the Federal Workforce and Agency Organization, Committee on Government Reform, United States House of Representatives.

Zain, J. (2004, October). Netcentricity and net ready. It is more than information/data interoperability (From the Defense Acquisition University Acquisition Community Connection). Retrieved December 14, 2006, from http://www.dau.mil/conferences/presentations/2004_peo_syscom/Wednesday/Session\%20B4/B4\%20Z avin.pdf 


\section{Biographies}

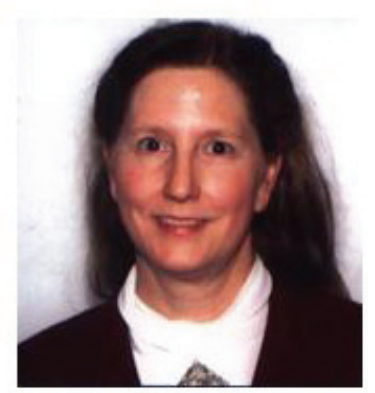

Dr. McCully, Chair and Professor, Information Strategies Department, IRM College, NDU. Chairs the Chief Information Officer (CIO) curriculum development that satisfies U.S. federal legislative and CIO Council mandates, and the Organization Transformation curriculum that educates strategic leaders to leverage the information component of national power to transform their organizations. She co-leads the College international partners educational programs.

Colonel McCully served 28 years in the US Air Force as a Long Range Strategy and Security Assistance Planner, Joint Staff; Pentagon; Dep-

uty Chief, Command, Control and Reconnaissance Division, AF Center for Studies and Analyses, Pentagon; Threat Assessment and Evaluation Analyst, North American Air Defense Command, Colorado and Thailand; Professor and Associate Dean, Industrial College of the Armed Forces; and Professor of Mathematics, US Air Force Academy.

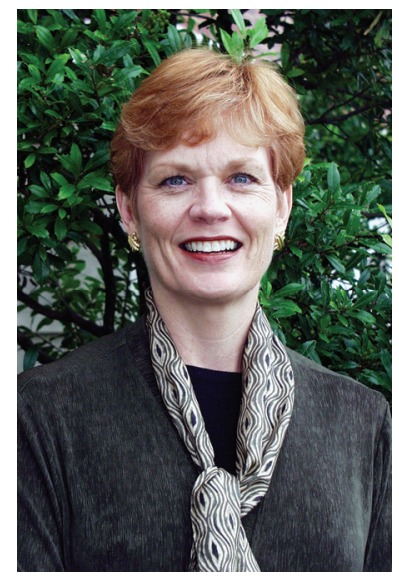

Elizabeth A. McDaniel is currently the Dean of Faculty and Academic Programs at Information Resources Management College, National Defense University. Dr. McDaniel earned a Ph.D. from the University of Miami, a master's degree from Barry University, and a bachelor's degree from the University of Florida. Her educational background in psychology and education underlie her commitment to teaching and learning. As a faculty member and campus leader, administrator, and scholar, she has focused on interdisciplinary education, general and liberal education, and innovation in curriculum and instruction. She is also experienced in strategic planning, multicultural and international issues, faculty collaboration, and e-learning. Her most recent writing relates to organizational agility, self-efficacy of higher education leaders, and leadership development. 